\title{
Uma tecnologia de saneamento ecológico para a recuperação de fósforo e reflexões sobre a prática de design tecnológico: incorporando valores socioambientais
}

\section{An ecological sanitation technology for a phosphorus recovery and reflections about the technological design: incorporating social and environmental values}

Data de entrada: 07/01/2019

Data de aprovação: $19 / 03 / 2019$
Vitor Tonzar Chaves ${ }^{1 *} \mid$ Ronan Cleber Contrera ${ }^{1}$

ORCID ID

Chaves VT (D) https://orcid.org/0000-0002-8106-5732
DOI: https://doi.org/10.36659/dae.2020.061

Contrera RC (D) https://orcid.org/0000-0002-3708-1743

\section{Resumo}

Tradicionalmente, o design das tecnologias sanitárias é pensado para a remoção de nutrientes. Para que sejam criadas soluções sanitárias capazes de aproveitar os recursos presentes no esgoto, é necessário que os engenheiros adequem sua forma de projetar. Neste trabalho é apresentada uma reflexão com o intuito de dialogar com a comunidade técnico-científica da área sobre a necessidade dessa inflexão na maneira de agir/pensar. Além disso, é apresentada uma tecnologia baseada nesses princípios que é capaz de promover a reciclagem do fósforo presente no esgoto. A tecnologia é composta por 4 reatores: fossa digestora, decantador, alagado construído vertical e alagado construído parcialmente preenchido com lodo de ETA. O sistema apresentou eficiência de remoção de $94,4 \% \pm 3,2 \%$ para DQQO e de $91,2 \% \pm 7,8 \%$ para sólidos suspensos. A eficiência de remoção do fósforo reativo solúvel $\left(\mathrm{P}_{\text {solúvel }}\right)$ foi de $95 \%$ e diminuiu até atingir a saturação do adsorvente. Os autores concluem que a aplicação do lodo férrico é interessante para promover uma tecnologia de baixo custo e baixa demanda operacional para recuperação de fósforo. O tempo de vida do adsorvente foi estimado entre 1,6 e 9,7 anos.

Palavras-chave: Sustentabilidade. Recuperação de Fósforo. Saneamento Ecológico. Lodo ETA. Alagados Construídos.

\section{Abstract}

Usually, the design of sanitary technologies is thought for the removal of nutrients. In order to promote nutrients recycling, new project design thinking has to be incorporated. This work starts with a reflection in order to dialogue with the community-scientific in this field. In addition, a technology based on these principles is presented. Its is capable of promoting the recycling of the phosphorus present in the sewage. The technology is composed of 4 reactors: digester pit, decanter, vertical constructed wetland and constructed wetland partially filled with ferric sludge. The system presented removal efficiency of $94.4 \% \pm 3.2 \%$ for COD and $91.2 \% \pm 7.8 \%$ for suspended solids. The efficiency of removal of the soluble reactive phosphorus $\left(P_{\text {soluble }}\right)$ was of $95 \%$ and decreased until reaching the saturation of the adsorbent. The authors conclude that the application of ferric sludge is interesting to promote a technology of low cost and low operational demand for recovery of phosphorus. The lifetime of the adsorbent was estimated between 1.6 and 9.7 years.

Keywords: Sustainability. Phosphorus Recovery. WTP Sludge. Constructed Wetlands. Ecological Sanitation.

\footnotetext{
${ }^{1}$ Universidade de São Paulo (USP) - São Paulo - São Paulo - Brasil.

* Autor correspondente: vitorasapienciaambiental.com/vitortchavesagmail.com.
} 
1 PARA COMEÇAR - REFLETINDO SOBRE A CONSTRUÇÃO DO PARADIGMA TECNOLÓGICO

\section{SANITÁRIO}

O enfoque tradicional do saneamento considera o esgoto como algo fétido e putrefato, o qual necessita ser afastado e tratado. Desta maneira, tradicionalmente, o design das tecnologias sanitárias é pensado para a remoção de nutrientes e para a construção de infraestruturas centralizadas baseadas em grandes ETEs e redes de coleta. Contudo, a carência de infraestruturas adequadas de saneamento no Brasil, quase 100 anos depois da construção da primeira estação de tratamentos de esgoto no país, parece fornecer evidências empíricas de que esse paradigma tradicional não foi capaz de resolver boa parte de nossos problemas sanitários.

Muitos municípios brasileiros não contam com infraestruturas para o tratamento de esgoto: dados apresentados pelo Atlas do Saneamento Básico (IBGE, 2011) mostram que apenas um terço dos municípios realizou tratamento de esgotos. Isso mostra que o problema do esgotamento sanitário não atinge apenas as grandes metrópoles, uma vez que $68,4 \%$ dos municípios brasileiros possuem até 20 mil habitantes (IBGE, 2016). Grande parte desses municípios sofre com a falta de sistemas de tratamento de esgoto, seja por motivos financeiros ou por carência de capacidade técnica em operá-los. Dados do Diagnóstico dos Serviços de Água e Esgoto 2013 (BRASIL, 2013) mostram que no Brasil coleta-se apenas $48,6 \%$ do esgoto gerado. Deste total, $69,4 \%$ são tratados, ou seja, na realidade trata-se apenas $39 \%$ do total de esgoto gerado no país. No que se refere à qualidade do esgoto tratado, as ETEs em operação são projetadas para remoção de matéria orgânica, sendo a remoção de nutrien- tes baixa e incapaz de atender aos parâmetros de lançamento (OLIVEIRA e VON SPERLING, 2005)'1.

Como resultado do excesso de nutrientes lançados nos corpos hídricos, tem-se a eutrofização. No Estado de São Paulo, relatório publicado pela Cetesb mostra que $63 \%$ dos pontos monitorados apresentaram resultados não-conformes com as determinações da Conama 357/05 em termos de fósforo dissolvido, sendo esse porcentual maior do que a média de 2011-2015, que era de 54\% (CETESB, 2016). O relatório conclui que $45 \%$ dos pontos avaliados estão em processo de eutrofização e $21 \%$ encontram-se eutrofizados.

Diante dos problemas ambientais encontrados mundo afora, cresce o debate no campo do saneamento a respeito do paradigma tecnológico herdado de uma sociedade que ainda não estava consciente da dimensão da crise ecológica na qual o planeta se encontrava. Acredita-se que tais tecnologias são limitadas para construir uma sociedade mais sustentável, pois não levam em conta as possibilidades de reaproveitamento hídrico, energético e de nutrientes existentes no tratamento de esgotos (LARSEN et al., 2016; MASI et al., 2017).

Buscando contribuir para a construção de uma sociedade mais sustentável, este artigo propõe uma tecnologia de baixo custo, capaz de tratar o esgoto de maneira descentralizada e de promover a reciclagem de fósforo. Tal tecnologia foi concebida a partir da incorporação de valores socioambientais, tais como criar alternativas tecnológicas de baixa demanda operacional que poderiam ser mantidas por comunidades rurais/peri-urbanas; utilizar de maneira benéfica o lodo de ETA gerado nas cidades; contribuir para a minimização dos problemas causados pela eutroficação.

\footnotetext{
${ }^{2}$ Apesar de ser um estudo de 2005, pouco mudou, visto que as ETEs são, em geral, Lodos Ativados, tratamentos anaeróbios e sistemas de lagoas, tecnologias que não permitem uma remoção significativa de nitrogênio total e fósforo.
} 
Acredita-se que, para que os engenheiros possam adequar sua forma de pensar/agir, de modo a considerarem a incorporação de valores socioambientais no design tecnológico, é importante que reflitam sobre as origens das atuais tecnologias hegemônicas, consolidadas pelo paradigma tradicional do saneamento. A partir do estudo de sua história, é possível compreender que as escolhas tecnológicas são fruto de um complexo processo sócio-histórico, condicionado por valores socialmente instituídos, ancorados por uma série de fatores políticos, econômicos, culturais e institucionais, entre outros (DOSI, 1982; FEENBERG, 2002).

A influência de elementos sociais e políticos no desenvolvimento das tecnologias, apesar de poderem ser identificados por uma análise histórica, muitas vezes não são percebidos pelos engenheiros. Como resultado, muitas das práticas de projetos e dos valores inerentes à comunidade técnica, como por exemplo, o uso de concreto nas construções civil ou o uso de sistemas centralizados de coleta de esgoto com tratamento em lodos ativados, passam a ser adotadas como práticas indiscutíveis. Tornam-se "escolhas óbvias" e passam a ser reproduzidas sem questionamento por muitas gerações de profissionais. Desse modo, várias dessas soluções e formas de pensar passam a constituir um paradigma.

O conceito de "paradigma" foi amplamente difundido a partir do célebre ensaio de Thomas Kuhn de 1962, A estrutura das revoluções científicas. O paradigma determina quais tipos de problema serão estudados e quais metodologias, teorias e instrumentos serão aplicados para sua resolução (KUHN, 2017). Dosi (1982), baseandose na tese de Kuhn, argumenta que o desenvolvimento tecnológico, assim como o científico, não pode ser explicado por uma lógica autônoma inerente a esse campo. Segundo sua teoria, na produção tecnológica, assim como ocorre na científica, existem paradigmas que norteiam os rumos do desenvolvimento técnico, sendo sua constituição dada por elementos sociais, políticos/institucionais, técnicos e econômicos que operam como dispositivos de seleção, delimitando as possibilidades tecnológicas. Soluções que não fazem parte do paradigma vigente não são sequer consideradas pela comunidade técnicocientífica (DOSI, 1982). Cada paradigma tecnológico está atrelado a um conceito de progresso, a uma proposta de desenvolvimento e, portanto, sua mudança, dependerá de fatores extrínsecos à técnica.

Dessa maneira, o "paradigma" é caracterizado por nortear o desenvolvimento tecnológico ao definir quais problemas são considerados relevantes e quais métodos, teorias e artefatos tecnológicos são considerados legítimos pela comunidade técnico-científica para resolvê-los, resultando na institucionalização de um certo grupo de tecnologias como "soluções eficientes". Tais soluções são amplamente - e quase que indiscutivelmente - aceitas pela comunidade técnico-científica e são repassadas para as gerações futuras através dos livros e manuais técnicos e dos cursos ministrados nas escolas de engenharia.

As raízes do que se denomina de "paradigma tradicional do saneamento" podem ser remontadas à Inglaterra após a Revolução Industrial. Neste período houve o inchaço dos centros urbanos, os quais devido à carência de infraestruturas sanitárias viraram núcleos de propagação de doenças como cólera e febre tifo. Tal contexto, associado à produção e disseminação de tecnologias como as tubulações de ferro dúctil e a descarga hidráulica, configuraram o início do desenvolvimento das tecnologias sanitárias modernas. A produção industrial de tubulações de ferro favoreceu a disseminação dos banheiros com descarga hidráulica, que começaram a se tornar usuais por volta de 1810 na Grã-Bretanha. Antes disso, e durante quase todo século XIX, em muitas das 
cidades europeias eram utilizadas latrinas (REZENDE e HELLER, 2008).

Neste período a teoria miasmática era a explicação mais aceita pela comunidade científica acerca da transmissão de doenças. Esta postulava que as doenças eram veiculadas pelos odores fétidos da matéria orgânica em depuração. Por esta razão não se compreendia o risco epidemiológico em se utilizar os rios como veículo para o esgoto, o objetivo era afastá-lo o mais rápido possível (HALLIDAY, 2001; REZENDE e HELLER, 2008).

Nessa época, apesar de não se entender a necessidade de tratamento de esgotos e a transmissão de doenças, a possibilidade de reaproveitamento dos nutrientes presentes no esgoto era conhecida e praticada. Os trabalhos publicados por Justus von Liebig foram fundamentais para a compreensão de que as plantas necessitavam de uma série de minerais para seu desenvolvimento, tais como o potássio e o fósforo, que poderiam ser encontrados no esgoto (HAMLIN, 1980). Por essa razão, Liebig defendia que os nutrientes encontrados no esgoto deveriam retornar para o solo e não ser desperdiçados e lançados diretamente na água. Sua publicação no ano de 1840 , Chemistry in Its Applications to Agriculture and Physiology, intentou fornecer bases teóricas para tal (HAMLIN, 1980). Muitas cidades na Europa, como Paris, Berlim, Milão, Edimburgo e outras adotaram a disposição no solo com produção de alimentos como solução. Quando bem operadas, essas "fazendas de esgoto" eram muito seguras. Contudo, a falta de compreensão dos processos microbiológicos atuantes no solo e a falta de tecnologias adequadas de tratamento prévio fez com que muitas das áreas destinadas a esse fim se transformassem em alagados mal cheirosos devido à sobrecarga do potencial de tratamento dos solos. Além disso, esse tipo de solução exigia grandes extensões de terra, as quais ficavam longe dos centros urbanos, acarretando em altos custos de transporte (HAMLIN, 1980).

No final do século XIX houve importantes avanços científicos que contribuíram para que os processos de decomposição da matéria orgânica fossem melhor compreendidos, como o trabalho de Schloesing e Muntz (1877, apud HAMLIN, 1980) e o trabalho de Mather e Platt (1893, apud ALLEMAN e PRAKASAM, 1983), entre muitos outros que culminaram nas primeiras ETEs de lodos ativados em batelada na Inglaterra no ano de 1914 (ALLEMAN e PRAKASAM, 1983). Depois que os processos biológicos de tratamento aeróbio passaram a ser melhor compreendidos e o projeto das estações de tratamento foi melhorado, perderam-se de vista as soluções que buscavam reaproveitar os nutrientes e o esgoto passou a ser visto como algo a "ser tratado" (HAMLIN, 1980).

Paralelamente, no Brasil, a evolução das infraestruturas sanitárias se deu de maneira diferente, muito mais lenta. No final do século XIX, esse setor era dominado por empresas de capital inglês, que, apesar de prometerem a promoção da modernização urbana, condicionaram que o atendimento fosse estruturado apenas nas regiões ocupadas por consumidores com capacidade de pagamento para remunerar os capitais aplicados. Assim, nunca foram capazes de atender à população mais pobre, largada em segundo plano (MURTHA, CASTRO e HELLER, 2015; REZENDE e HELLER, 2008). O saneamento evoluiu a passos lentos no Brasil, de maneira que em 1950 aproximadamente 1500 municípios, de um total de 1900, ainda não contavam com sistema de abastecimento de água (REZENDE e HELER, 2008). Durante a ditadura militar, no ano de 1970, houve a implementação de um novo plano nacional, conhecido como Plano Nacional de Saneamento (Planasa). Tal plano trouxe importantes avanços: entre 1970 e 1985 aumentou de 26,7 milhões para 82,8 milhões 
o número de brasileiros abastecidos com água potável (COSTA e RIBEIRO, 2013). Contudo, as ações foram realizadas em áreas nas quais se esperava retorno garantido dos investimentos. Assim, privilegiaram-se regiões mais ricas do Sul e Sudeste, concentrando a maior parte dos investimentos nas cidades mais populosas e, nestas, nos segmentos de maior renda. Além disso, os investimentos realizados no Planasa priorizaram os serviços de abastecimento de água em detrimento do esgotamento sanitário, devido ao maior lucro e amortização dos investimentos gerados por esses (COSTA e RIBEIRO, 2013; HELLER, 2007). Como consequência dessa lógica, essa política foi limitada para atender às demandas de esgotamento sanitário das cidades com menos de 20.000 habitantes (HELLER, 2007) e para fornecer acesso aos serviços de saneamento de grande parte da população mais carente (REZENDE e HELLER, 2008).

Foi no escopo da busca por alternativas tecnológicas capazes de promover a sustentabilidade e de resolver os problemas sanitários de países latinoamericanos, africanos e asiáticos, que emergiu o conceito do saneamento ecológico no final do século XX. Um dos primeiros trabalhos a sistematizar suas técnicas e práticas referentes foi publicado pela Agência Sueca de Cooperação Internacional para o Desenvolvimento com o título Ecological Sanitation (ESREY et al.,1998). Essa publicação tinha como intuito disseminar práticas e tecnologias que permitissem a países em desenvolvimento promover soluções descentralizadas de saneamento capazes de manter um meio ambiente salubre e contribuir para a superação de situações de escassez hídrica, além de garantir a segurança alimentar dessas populações graças ao reaproveitamento agrícola dos nutrientes contidos nos resíduos.

Atualmente o saneamento ecológico é compreendido como uma forma de pensar/projetar, e não apenas um certo leque de soluções alterna- tivas pré-definidas. Como Langergraber e Muellegger (2005) concluem, o saneamento ecológico representa uma mudança de atitude baseada em uma abordagem sistêmica. Trata-se, portanto, de uma nova racionalidade, de uma forma de design baseada em princípios e valores de cuidado com o meio ambiente, sustentabilidade e reciclagem de nutrientes, água e matéria orgânica. Nenhuma tecnologia, portanto, pode ser considerada intrinsecamente ecológica, uma vez que isso dependerá de seu contexto de aplicação. O saneamento ecológico considera a água, os nutrientes e a matéria orgânica presentes nos resíduos sólidos e no esgoto como preciosos recursos pertencentes a um ciclo natural. A partir dessa visão, propõem a promoção de práticas agrícolas sustentáveis a partir da reciclagem desses recursos. Dessa forma, o ser humano, a água, os nutrientes e a matéria orgânica são vistos como partes de um ecossistema, constituindo um ciclo fechado e harmônico (ESREY et al., 1998; HAQ e CAMBRIDGE, 2012; HU et al., 2016; LANGERGRABER e MUELLEGGER, 2005).

As soluções descentralizadas e que incorporam os princípios do saneamento ecológico podem ser aplicadas não só nas zonas rurais, como também nos centros urbanos (LARSEN et al., 2016). Usualmente, os sistemas de saneamento ecológico possuem caráter descentralizado, seja em nível individual/familiar ou comunitário, devido aos menores custos de operação e implantação e do maior potencial de reaproveitamento dos nutrientes dos sistemas descentralizados. Contudo, deve-se ressaltar que uma simples mudança de escala (de sistema centralizado para descentralizado) não garante que uma solução será efetivamente ecológica, tampouco que irá, por si só, gerar mudanças sociais ou políticas significativas (BELL, 2015). Em geral, o sucesso de políticas ambientais e sanitárias não depende apenas da aplicação de conhecimentos científicos e tecnológicos disponíveis, sendo a educação ambiental um fator chave para seu sucesso (JACOBI, 2003). 
Observa-se que o saneamento ecológico traz importantes contribuições para a construção de um novo paradigma, prezando pelo restabelecimento dos ciclos metabólicos locais, reciclagem de recursos presentes no esgoto e a promoção da universalização de infraestruturas sanitárias adequadas para toda a população. É importante salientar que o saneamento ecológico não se trata de uma mudança de escala - do centralizado para o descentralizado - mas sim de uma outra forma de abordar os problemas e propor soluções, uma proposta de design baseada em princípios e valores de cuidado com o meio ambiente, sustentabilidade e reciclagem de nutrientes, água e matéria orgânica. Apesar disso, os sistemas descentralizados possuem um importante papel, pois, em muitos casos, são capazes de propiciar soluções em curto prazo devido ao seu menor custo e simplicidade. O saneamento ecológico reconhece que as soluções sanitárias desenvolvidas para atender às demandas dos grandes centros urbanos não são necessariamente eficazes para atender às cidades de menor porte, populações rurais, indígenas e demais comunidades tradicionais. Além disso, as tecnologias empregadas em nossa sociedade atualmente insustentável, provavelmente não o serão da mesma maneira em um paradigma sustentável.

Por esse motivo, a transição de paradigma é necessária para que novas formas de pensar e projetar soluções sejam instituídas. Tal mudança dependerá de fatores técnicos e da mudança dos engenheiros em sua forma de pensar/agir, porém requer, sobretudo, alterações em elementos extrínsecos à técnica: incorporação de novos valores, novas práticas de projeto, novos materiais, novos conhecimentos, arranjos políticos-institucionais, desenvolvimento de práticas pedagógicas de educação ambiental e acordos tácitos entre os profissionais.

Por essa razão, neste trabalho fez-se o esforço de sistematizar nesta introdução uma importan- te reflexão que aponta para a necessidade dessa transição paradigmática, dessa incorporação de valores socioambientais no design tecnológico, tradicionalmente direcionado pela busca pela ineficiência. Acredita-se que os engenheiros possuem um importante papel enquanto sujeitos que contribuem para construir essa realidade, que, simultaneamente, e, mutuamente, condiciona e é condicionada pelas tecnologias.

Com isso em vista, neste trabalho será proposta uma tecnologia inovadora, que é capaz de promover a reciclagem de fósforo, e cujo projeto foi concebido a partir de uma perspectiva sistêmica que buscou incorporar novos valores socioambientais ao design: reciclagem de nutrientes, operação simples (para se adequar às demandas de pequenos municípios e comunidades rurais), tratamento descentralizado e de baixo custo.

A tecnologia é composta por 4 reatores: fossa digestora, decantador, alagado construído vertical e alagado construído parcialmente preenchido com lodo férrico, oriundo de uma ETA da região metropolitana de São Paulo. O uso lodo férrico como adsorvente de fósforo é uma alternativa interessante e sustentável capaz de concentrar o fósforo no lodo férrico originado em áreas urbanas e aplicálo como um melhorador do solo em áreas rurais e periurbanas. Com isso, contribui-se para reduzir a eutrofização dos corpos hídricos lênticos graças à redução da descarga de esgoto, e ainda, garantir a segurança alimentar global.

\section{OBJETIVOS}

\subsection{Objetivo Geral}

Apresentar uma tecnologia de saneamento ecológico pensada para promover a reciclagem de fósforo e o tratamento de esgoto de maneira simples e barata, bem como refletir sobre o papel dos engenheiros para que um outro paradigma seja estabelecido. 


\subsection{Objetivos Específicos}

- Monitorar o desempenho de uma tecnologia de tratamento descentralizado de esgoto (DQO, Sólidos Suspensos, Fósforo) sustentável e de baixo custo, capaz de promover a recuperação de fósforo.

- Avaliar o tempo de vida útil do lodo de ETA que é proposto como um material de preenchimento para alagados construídos, capaz de remover fósforo do esgoto e promover sua recuperação após a saturação.

\section{METODOLOGIA}

\subsection{A concepção tecnológica}

A tecnologia proposta foi concebida para ser um sistema de tratamento de baixo custo que pode ser facilmente instalado em áreas rurais e periurbanas. Esse tipo de sistema descentralizado poderia ser operado por agricultores e pequenas comunidades porque requer pouca manutenção e controle operacional. O fluxo diário influente de $360 \mathrm{~L}$ dia-1 foi considerado para o projeto do sistema, o que equivale aproximadamente ao consumo de uma família de 3 pessoas (ABNT, 1993). Para controlar o fluxo afluente, utilizou-se uma bomba Nietzsche, modelo NM021BY, acoplada a um inversor de frequência Weq, modelo CFW-08, e um temporizador digital Coel, modelo BWT-40. A tecnologia proposta foi composta por quatro reatores:

1) Fossa séptica de fluxo ascendente: um tanque de água comercial de $1000 \mathrm{~L}$;

2) Decantador: caixa d'água de 500 L. Esse reator foi concebido para reter sólidos suspensos oriundos do tanque séptico e, com isso, evitar o entupimento do alagado construído subsequente;

3) Alagado construído de fluxo ascendente: tanque de água de $1000 \mathrm{~L}$ com diâmetro interno médio de $1,35 \mathrm{~m}$, preenchido com cascalho de diâmetro efetivo (d10) de 7,85 mm, coeficiente de uniformidade de 1,44 e porosidade de 0,45. Espécies de brejo foram plantadas: Canna $\times$ generalis, Coix lacryma-jobi, Dioscorea spp e Zingiber officinale.

4) Alagado construído parcialmente preenchido com lodo férrico: foi utilizado um tanque de 1000 $\mathrm{L}$ com diâmetro interno médio de 1,35 m, preenchido com brita e uma camada de $2 \mathrm{~mm}$ de lodo férrico $(3,17 \mathrm{~kg}$, massa seca), coberto com uma camada de brita de $5 \mathrm{~mm}$. A pequena quantidade de lodo férrico introduzida foi intencional para fornecer informações sobre o tempo de saturação em curto prazo. Dez mudas de gengibre (Zingiber officinale) retiradas de um pântano natural no campus da universidade foram plantadas. A taxa de carga hidráulica foi de $0,27 \mathrm{~m}^{3} \mathrm{~m}^{-2} \mathrm{~d}^{-1}$.

\subsection{0 monitoramento do sistema}

As três primeiras etapas do sistema foram previamente monitoradas por 300 dias, antes da instalação da quarta etapa, certificando-se de que o sistema era capaz de remover o fósforo do esgoto.

Depois de completado, o sistema foi monitorado ao longo de 83 dias. Durante esse período, 18 amostras foram coletadas para determinar as concentrações de DQQO, sólidos suspensos, fósforo total $\left(P_{\text {total }}\right)$ e fósforo reativo solúvel $\left(P_{\text {solúvel }}\right)$ no afluente e no efluente. Todas as concentrações das variáveis foram determinadas seguindo os métodos padrão descritos por APHA, AWWA e WEF (2017) e listados na Tabela 1.

Tabela 1 - Métodos usados para determinar a concentração de DQQO, sólidos suspensos e fósforo

\begin{tabular}{|c|c|}
\hline $\begin{array}{c}\text { Variável } \\
\text { Demanda Química de Oxigênio } \\
\text { (DQO) }\end{array}$ & Método \\
\hline Sólidos suspensos & SM 5220-D \\
\hline Fósforo total & SM 2540-D \\
\hline Fósforo reativo solúvel & SM 4500-P B4 and SM 4500-P E \\
\hline
\end{tabular}


3.3 Caracterização do lodo de ETA utilizado e de seu desempenho como adsorvente de fósforo

O lodo férrico utilizado nesse estudo foi obtido na Estação de Tratamento de Água de Cubatão, onde ele foi desaguado por meio de centrífugas e com adição de polímeros pré-centrífuga. Possuía inicialmente teor de sólidos de aproximadamente $20 \%$ e idade do lodo de 93 dias e foi deixado 3 semanas em ambiente abrigado de chuva, porém exposto ao sol e vento, com o intuito de secá-lo. Em seguida, realizou-se o quarteamento da amostra e o lodo selecionado foi moído e peneirado, obtendo-se um material com diâmetro menor que $2 \mathrm{~mm}$. A fração quarteada da amostra foi devidamente acondicionada e dessa porção foram selecionadas as amostras utilizadas para caracterização de sua massa férrica e para a determinação de sua porosidade e densidade antes de utilizá-las como meio de preenchimento do alagado construído.

Para caracterizar a sua composição férrica foi utilizada amostra em triplicata com quantidade significativa de lodo seco. $O$ método de digestão aplicado foi SM 3030 F (APHA, AWWA e WEF, 2017) e o procedimento de caracterização foi realizado com um espectrômetro de absorção atômica Varian, modelo 214 FS, seguindo SM 3111 B: Método de Chama a Ar-Acetileno Direto (APHA, AWWA e WEF, 2017).

Para calcular a massa removida de fósforo total e de fósforo reativo solúvel foi aplicado método dos trapézios para obter a integral da série temporal determinada com as amostras. Embora se saiba que uma certa porção se refere à assimilação biológica do crescimento de microrganismos, isso será desprezado nos cálculos de capacidade de adsorção, já que a remoção da adsorção é considerada muito mais significativa. Todo o fósforo solúvel removido é considerado transferido para a superfície adsorvente. Sendo a vazão diária considerada de 360 L, a equação utilizada foi a seguinte:
Massa removida $(\mathrm{g})=$

$$
\left(\frac{C_{i(j+a)}-C_{e(j+1)}+\left(C_{i j}-C_{e j}\right)}{2}\right) t_{j(j+1) \cdot 0,36}
$$

No qual,

$\mathrm{C}_{\mathrm{ij}}=$ concentração de fósforo afluente no dia de operação j ( $\left.\mathrm{mgPO}_{4}{ }^{-} \mathrm{P} . \mathrm{L}^{-1}\right)$

$C_{e j}=$ concentração de fósforo efluente no dia de operação j $\left(\mathrm{mgPO}_{4}{ }^{-P} \cdot \mathrm{L}^{-1}\right)$

$t_{j(j+1)}=$ tempo de operação entre os dias j e j+1

\section{AVALIAÇÃO DA TECNOLOGIA DE SANEAMENTO ECOLÓGICA PROPOSTA E O LODO FÉRRICO COMO ADSORVENTE DE FÓSFORO}

A tecnologia proposta tem como intuito concentrar o fósforo no lodo férrico originado em áreas urbanas e aplicá-lo como um melhorador do solo em áreas rurais e periurbanas; ajudar a garantir a segurança alimentar global graças à recuperação do fósforo; e reduzir a eutrofização em corpos hídricos lênticos graças à redução da descarga de nutrientes do esgoto.

A disposição indevida do lodo oriundo das estações de tratamento de água (ETAs) em corpos hídricos sem tratamento prévio é uma prática recorrente no Brasil. Achon e Cordeiro (2015), ao analisar a destinação do lodo gerado por 22 ETAs de 15 municípios localizados em uma mesma subbacia hidrográfica no Estado de São Paulo, constataram que $86 \%$ das ETAs lançam o lodo sem tratamento nos corpos d'água, $9 \%$ destinam o lodo para uma Unidade de Tratamento de Resíduos e $5 \%$ encaminham o lodo para uma da ETEs do município. No Estado de Minas Gerais, a situação é similar. Dados coletados de 175 municípios mostram que $87 \%$ das ETAs dos municípios avaliados lançam o lodo em corpos d'água sem tratamento (MINISTÉRIO PÚBLICO DO ESTADO DE MINAS GERAIS, 2009). Quando despejado nos corpos hídricos, pode causar sérios impactos ao ecossistema. Barbosa (2000) realizou estudos de toxidade para 
caracterizar o impacto do lodo à biota aquática. A autora concluiu que havia indícios de toxidade a microcrustáceos, quiromídeos e peixes.

Desse modo, é inadmissível que esses resíduos sejam despejados despreocupadamente nos corpos hídricos. Os aterros sanitários e as estações de tratamento de esgotos são algumas das alternativas convencionais utilizadas. Há membros da comunidade técnico-científica que defendem o tratamento do lodo de ETA enviando-o para as ETEs como uma alternativa para casos em que as ETAs já estão construídas em áreas densamente urbanizadas, onde não há área para construção de sistemas de tratamento dentro da unidade (MARGUTI et al., 2018). Contudo, as características desse tipo de lodo são muito diferentes daquelas do esgoto afluente às ETEs, de modo que o seu lançamento nelas pode ser considerado como apenas uma transferência do problema. $O$ lodo de ETA é predominantemente formado por sólidos inorgânicos, os quais não são degradados por processos biológicos como os lodos ativados. Assim, resultam no aumento da geração de lodo da ETE, o qual, por sua vez, terá menor potencial de geração de biogás e será mais difícil de ser desaguado (DESMIDT et al., 2015; SMITH e CARLIELL-MARQQUET, 2009).

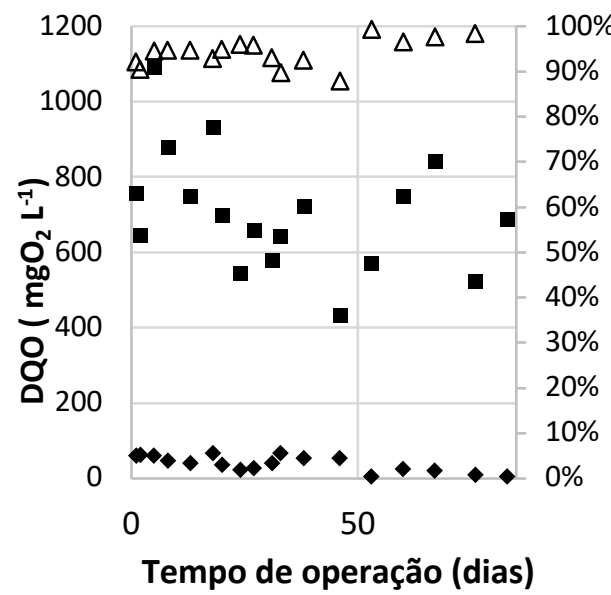

(a)
A disposição do lodo em aterros sanitários também é considerada uma solução a ser evitada, uma vez que os aterros possuem vida útil limitada e alto custo de implantação. Além disso, os lodos apresentam alta plasticidade, baixa resistência ao cisalhamento, baixa permeabilidade à água e são extremamente compressíveis e tixotrópicos. Dessa forma, se eles não forem desaguados adequadamente, antes de serem dispostos no aterro, causam problemas estruturais ao mesmo. Teores de 25 a 30\% de sólidos e tensão de cisalhamento superior a $25 \mathrm{kPa}$ têm sido recomendados para essa disposição (O’KELLY, 2016).

\subsection{DQO e Sólidos suspensos}

A tecnologia proposta apresentou eficiência de remoção de $94,4 \% \pm 3,2 \%$ para DOQO e de $91,2 \%$ $\pm 7,8 \%$ para sólidos suspensos. A Fig. 1 a e a Fig. 1b mostram como se comportou a remoção desses parâmetros ao longo do tempo de operação. A concentração do afluente apresentou oscilações consideráveis, mas a característica de efluentes foi estável, sugerindo que o sistema de tratamento avaliado é resiliente e estável em termos de remoção de matéria orgânica e sólidos.

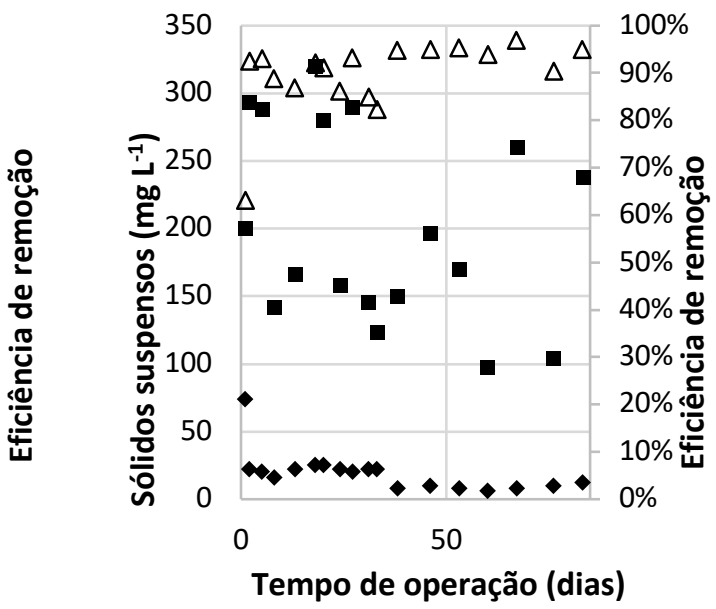

(b)

Fig. 1 - Concentrações afluentes ( $\square$ ) e efluentes $(\downarrow)$ ao longo da operação, e eficiência de remoção $(\Delta)$ da $\mathrm{DQQO}(\mathrm{a})$ e sólidos suspensos(b) 


\subsection{Fósforo}

$\mathrm{O}$ alagado construído parcialmente preenchido com o lodo férrico foi o reator responsável pela remoção de fósforo. A pequena quantidade de lodo introduzida foi intencional para fornecer informações sobre o tempo de saturação em 100 dias no máximo. Os três primeiros reatores já haviam sido monitorados por 300 dias e não apresentaram remoção de fósforo.

O teor de massa férrica determinado para o lodo foi de $273,1 \pm 17,4 \mathrm{mg} \mathrm{g}^{-1}$. Este tinha uma densidade de 1,50 $\pm 0,13 \mathrm{~g} \mathrm{~cm}^{-3}$ e uma porosidade de $42 \% \pm 3 \%$, semelhante aos materiais típicos de preenchimento de zonas húmidas (BABATUNDE et al., 2009; KADLEC e WALLACE, 2009). O fósforo total afluente e efluente e o fósforo reativo dissolvido foram monitorados por 83 dias. Os resultados são mostrados na Fig. 2. Observou-se um rápido decréscimo na eficiência de remoção de $\mathrm{P}_{\text {solúvel }}$, o que pode estar associado à pequena disponibilidade de superfície adsorvente, devido à pequena quantidade de lodo aplicada $(3,17$ $\mathrm{kg}$, massa seca). A primeira amostra apresentou uma eficiência de remoção de 95\%. A amostra coletada no segundo e quinto dia, respectivamente, apresentou $72 \%$ e $60 \%$. Após 60 dias de operação, as eficiências de remoção de $\mathrm{P}_{\text {solúvel }}$ ficaram abaixo de $10 \%$, indicando que o ponto de saturação havia sido atingido.

A eficiência de remoção de $P_{\text {total }}$ também mostra uma tendência decrescente, mas apresenta mais oscilações ao longo do período monitorado. Formas não solúveis de fósforo são encontradas ligadas à matéria orgânica e seus mecanismos de remoção dependem de outros processos, como filtração, aprisionamento físico e sedimentação no leito.

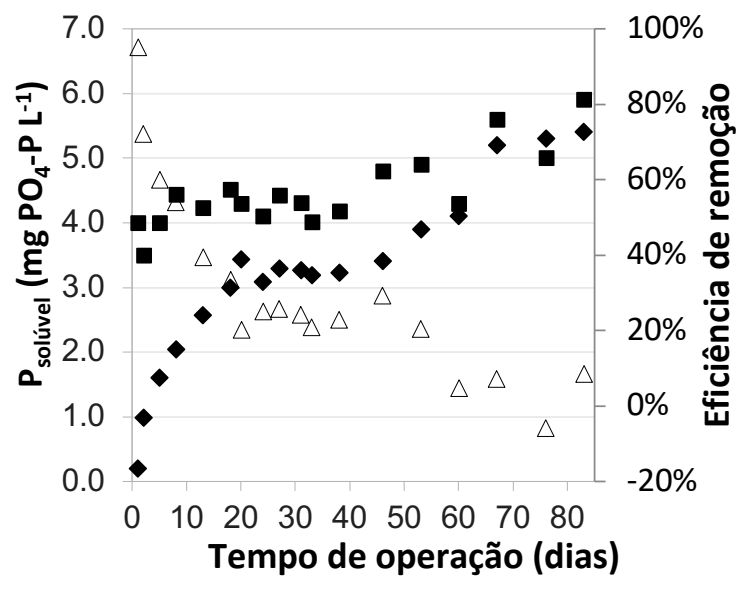

(a)

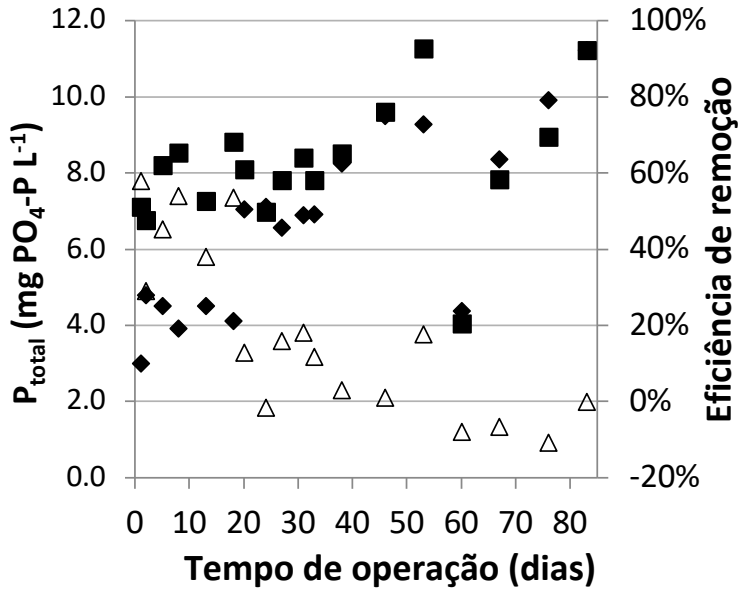

(b)

Fig. 2 - Performance do alagado construído parcialmente preenchido com lodo férrico: concentrações afluente ( $\mathbf{\square})$ e efluente $(\diamond)$ e eficiência de remoção $(\Delta)$ para Psolúvel (a) e Ptotal (b) 
A Tabela 2 mostra a massa removida de fósforo total e fósforo reativo solúvel em diferentes períodos de operação.

Tabela 2 - Massa de Ptotal e Psolúvel removida ao longo da operação

\begin{tabular}{|c|c|c|c|c|}
\hline & $\mathbf{P}_{\text {total }}$ & & \multicolumn{2}{|c|}{$\mathbf{P}_{\text {solúvel }}$} \\
\hline Tempo de operação & Massa removida (g) & Massa removida $\mathbf{( g )}$ & $\mathbf{q}\left(\mathbf{m g P ~ g}^{-1}\right)$ & $\mathbf{P}_{\text {solúvel }} / \mathbf{P}_{\text {total }}$ \\
\hline 2 dias & 2.57 & 2.51 & 0.79 & 0.98 \\
\hline 5 dias & 5.63 & 5.16 & 1.63 & 0.92 \\
\hline 60 dias & 35.91 & 29.43 & 9.28 & 0.82 \\
\hline 83 dias & 31.16 & 30.60 & 9.65 & 0.98 \\
\hline
\end{tabular}

É observado na Fig. 2 que a eficiência de remoção do $P_{\text {solúvel }}$ foi maior que $60 \%$ durante os primeiros cinco dias de operação. Para este período, a relação entre o fosfato adsorvido e o lodo férrico aplicado foi de 1,63 $\mathrm{mg} \mathrm{P.g}^{-1}$ (ver Tabela 2). Embora as eficiências de remoção tenham diminuído drasticamente após o quinto dia, o lodo férrico ainda teve capacidade de adsorção até o $80^{\circ}$ dia de operação, quando atingiu a saturação. $A$ capacidade de adsorção de $9,65 \mathrm{mg} \mathrm{P.g}^{-1}$ foi determinada neste ponto. É importante ressaltar que a eficiência de remoção do reator é afetada por aspectos hidráulicos, como a ocorrência de caminhos de fluxo preferenciais no leito do alagado construído, o que pode reduzir o contato do poluente com o adsorvente.

Para estimar o tempo de vida útil do lodo férrico enquanto adsorvente, foi utilizada a seguinte expressão baseada em parâmetros de projeto típicos para caracterizar a operação:

$T V U=\frac{q \cdot T D H \cdot \rho_{\text {lodo }}}{(1-\eta) \cdot C_{\text {in }}} \cdot 2,74$

No qual,

TVU = Tempo de vida útil (anos)

$\mathrm{q}=$ capacidade de adsorção ( $\mathrm{mg} \mathrm{P} \mathrm{g}^{-1}$ )

TDH = tempo de detenção hidráulico (dias)

$\rho_{\text {lodo }}=$ massa específica do lodo férrico $\left(\mathrm{kg} \mathrm{dm}^{-3}\right)$

$\eta=$ eficiência de remoção do fosfato

$\mathrm{C}_{\text {in }}=$ concentração de fósforo reativo solúvel no afluente ( $\left.\mathrm{mg} \mathrm{PO}_{4}-\mathrm{P} \mathrm{L}^{-1}\right)$
Com isto, é possível estimar o tempo de vida que o reator poderia ter utilizando o lodo férrico como seu principal material de preenchimento. Assim, para $\mathrm{q}=1,63 \mathrm{mg} \mathrm{Pg}^{-1} ; \mathrm{TDH}=1,0 \mathrm{dia} ; \rho_{\text {lodo }}$ $=1,5 \mathrm{~kg} \mathrm{dm}^{-3} ; \eta=0,95$ e Cin $=4,5 \mathrm{mg} \mathrm{L}^{-1}$, a vida útil do adsorvente seria de 1,6 ano. Dependendo da eficiência de remoção desejada, a capacidade de adsorção do lodo pode ser considerada ainda maior. Se q = 9,65 mg P.g $\mathrm{g}^{-1}$ é considerado, a vida útil do adsorvente é de 9,7 anos. Esses valores são menores, mas comparáveis ao tempo de vida do lodo à base de alumínio determinado por Zhao et al. (2009), que concluíram que pode variar entre 4 e 17 anos.

Importante ressaltar que, depois de atingir sua saturação, o adsorvente precisa ser substituído. O lodo velho saturado de fósforo pode ser disposto em florestas, viveiros de plantas, parques públicos, campos de golfe, gramados, hortas, áreas agriculas e pastagens. Esse tipo de prática permite a assimilação do resíduo aplicado sem afetar adversamente a qualidade do solo e pode até melhorar as propriedades físicas do solo, como agregação do solo, capacidade de retenção de umidade e permeabilidade à água $(\mathrm{AH}-$ MAD et al, 2016).

\section{CONCLUSÃO}

Tecnologias sanitárias de baixo custo são necessárias para alcançar a sustentabilidade em países subdesenvolvidos e em desenvolvimento. 
Além disso, é fundamental que sejam pensadas tecnologias capazes de promover o reaproveitamento dos recursos contidos no esgoto. Assim, este estudo propôs um sistema de tratamento descentralizado, que requer pouca manutenção e controle operacional e que poderia ser operado por agricultores e pequenas comunidades. No presente estudo, a tecnologia foi projetada para um fluxo diário influente de $360 \mathrm{~L} \mathrm{dia}^{-1}$ e consistia de um tanque séptico de fluxo ascendente, um decantador, um alagado construído preenchido com brita e um alagado construído parcialmente preenchido com lodo de férrico. A taxa de carga hidráulica para os alagados construídos foi de $0,27 \mathrm{~m}^{3} \mathrm{~m}^{-2} \mathrm{~d}^{-1}$.

A tecnologia proposta apresentou eficiência de remoção de $94,4 \% \pm 3,2 \%$ para DQO e de $91,2 \%$ $\pm 7,8 \%$ para sólidos suspensos. A eficiência de remoção do fósforo reativo solúvel (Psolúvel) para esse sistema foi de $95 \%$ e diminuiu até atingir a saturação do adsorvente. Os autores concluem que a aplicação do lodo férrico em um alagado construído é uma alternativa interessante para promover uma tecnologia de baixo custo e baixa demanda operacional para recuperação de fósforo. O tempo de vida do adsorvente foi estimado entre 1,6 e 9,7 anos, dependendo da capacidade de adsorção do lodo férrico e da eficiência de tratamento necessária.

\section{AGRADECIMENTOS}

Agradecimentos ao CNPq pela bolsa de pesquisa 133676/2016-1 e à gestão da ETA Cubatão da Sabesp, que forneceu o lodo necessário à pesquisa.

\section{CONTRIBUIÇÃO DOS AUTORES}

Todos os autores contribuíram de forma igualitária.

\section{REFERÊNCIAS}

ABNT - Associação Brasileira de Normas Técnicas. NBR 7229 Projeto, construção e operação de sistemas de tanques sépticos. Rio de Janeiro, 1993.

ACHON, C. L.; CORDEIRO, J. S. Destinação e disposição final de lodo gerado em ETA-Lei 12.305/2010. In: 45a Assembleia Nacional do ASSEMAE-Saneamento Ambiental: políticas integradas com participação social, Poços de Caldas-MG, 2015. Anais...

ALLEMAN, J. E.; PRAKASAM, T. B. S. Reflections on seven decades of activated sludge history. Water Pollution Control Federation. vol 55, n 5, p. 436- 443.

AHMAD, T.; AHMAD, K.; ALAM, M.. Sustainable management of water treatment sludge through 3 ' $R$ ' concept. J. of Clean. Prod., 124, 1 - 13. 2016. https://doi.org/10.1016/j.jclepro.2016.02.073

APHA, AWWA e IWA. Standard Methods for the Examination of Water and Wastewater. 23 ed. Centennial Edition 2017.

BABATUNDE, A. O.; ZHAO, Y. Q.; BURKE, A. M.; MORRIS, M. A.; HANRAHAN, J. P. Characterization of aluminium-based water treatment residual for potencial phosphorus removal in engineered wetlands. Environmental Pollution, v. 157, p. 2830 - 2836, 2009. https://doi.org/10.1016/j.envpol.2009.04.016

BARBOSA, R. M. Avaliação do Impacto de Lodos de Estações de Tratamento de Água à Biota Aquática Através de Estudos Ecotoxicológicos. São Carlos, 2000. Tese (Doutorado) - Escola de Engenharia de São Carlos, Universidade de São Paulo.

BELL, S. Renegotiating urban water. Progress in planning, v. 96, p. 1-28, 2015. https://doi.org/10.1016/j.progress.2013.09.001

BRASIL, Ministério das Cidades, Secretaria Nacional de Saneamento Ambiental. Plano Nacional de Saneamento Básico PLANSAB. Brasília. 2013a.

CETESB. Relatório de qualidade das águas superficiais do estado de São Paulo. 2016. Disponível em: http://aguasinteriores.cetesb.sp.gov.br/publicacoes-e-relatorios/ Data de Acesso: 10.maio.2018.

COSTA, S. S.; RIBEIRO, W. A. Dos porões à luz do dia. Um itinerário dos aspectos jurídicoinstitucionais do saneamento básico no Brasil. In: HELLER, L.; CASTRO, JE Política pública e gestão de serviços de saneamento. Belo Horizonte: Ed. UFMG, p. 467-482, 2013.

DESMIDT, E. et al. Global phosphorus scarcity and full-scale P-recovery techniques: a review. Critical Reviews in Environmental Science and Technology, v. 45, n. 4, p. 336-384, 2015. https://doi. org/10.1080/10643389.2013.866531

DOSI, G. Technological paradigms and technological trajectories: a suggested interpretation of the determinants and directions of technical change. Research policy, v. 11, n. 3, p. 147-162, 1982.

ESREY, S. A. et al. Ecological sanitation. Sida, 1998. 
FEENBERG, A. Transforming technology: a critical theory revisited. Oxford University Press, 2002.

HALLIDAY, S. Death and miasma in Victorian London: an obstinate belief. BMJ: British Medical Journal, v. 323, n. 7327, p. 1469, 2001. https://doi.org/10.1136/bmj.323.7327.1469

HAQ, G.; CAMBRIDGE, H. Exploiting the co-benefits of ecological sanitation. Current Opinion in Environmental Sustainability 4, p. 431-435, 2012. https://doi.org/10.1016/j.cosust.2012.09.002

HAMLIN, C. Sewage: Waste or resource? A historical perspective. Environment: Science and Policy for Sustainable Development, v. 22 , n. 8, p. $16-42,1980$

HELLER, L. Basic sanitation in Brazil: lessons from the past, opportunities from the present, challenges for the future. Journal of Comparative Social Welfare, v. 23, n. 2, p. 141-153, 2007. https://doi.org/10.1080/17486830701494640

HU, M. et al. Constructing the ecological sanitation: A review on technology methods. Journal of Cleaner Production, 2016a. In press. Disponível em: <HTTP:// dx.doi.org/10.1016/j.jclepro.2016.03.012>

IBGE, Instituto Brasileiro de Geografia e Estatística. Atlas do Saneamento Básico. Rio de Janeiro, 2011.

IBGE, Instituto Brasileiro de Geografia e Estatística. Estimativas populacionais para os municípios e para as Unidades da Federação brasileiros em 01.07.2016. Brasil, 2016.

JACOBI, P. R. Educação ambiental, cidadania e sustentabilidade. Cadernos de pesquisa, n. 118, p. 189-205, 2003. https://doi. org/10.1590/S0100-15742003000100008

KADLEC, R. H.; WALLACE, S. D. Treatment Wetlands. 2. ed. Florida: Taylor \& Francis, 2009.

KUHN, T. S. A estrutura das revoluções científicas. Tradução Beatriz Vianna Boreira e Nelson Boeira. 13 ed. São Paulo: Perspectiva, 2017. $260 \mathrm{p}$.

LANGERGRABER, G.; MUELLEGGER, E. Ecological sanitation - A way to solve global sanitation problems?. Environment International 31, p. 433 - 444. 2005. https://doi.org/10.1016/j.envint.2004.08.006

LARSEN, T. A.; HOFFMANN, S.; LUTHI, C.; TRUFFER, B.; MAURER, $M$. Emerging solutions to the water challenge of na urbanizing world. Science, v. 352, n. 6288, p. 928 - 933, 2016. https://doi/ org/ 10.1126/science.aad8641

MARGUTI, A. L., FERREIRA FILHO, S. S., PIVELI, R. P. Full-scale effects of addition of sludge from water treatment stations into processes of sewage treatment by conventional activated sludge. J. Env. Man. 215, 283 - 293, 2018. https://doi.org/10.1016/j.jenvman.2018.03.072

MASI, F.; RIZZO, A.; REGELSBERGER, M. The role of constructed wetlands in a new circular economy, resource oriented, and ecosystem services paradigm. Journal of Environmental Management, p. 1 - 10, 2017. https://doi.org/10.1016/j.jenvman.2017.11.086

MINISTÉRIO PÚBLICO DO ESTADO DE MINAS GERAIS. (2009) Parecer Técnico - Ref.: Ofício 1139/2008 (CAO-MA) - Informações técnicas referentes aos danos ambientais decorrentes do lançamento de lodo in natura, pelas Estações de Tratamento de Água, no ambiente. Belo Horizonte: Procuradoria-Geral de Justiça, $32 \mathrm{p}$.

MURTHA, N. A.; CASTRO, J. E.; HELLER, L. Uma Perspectiva Histórica das Primeiras Políticas Públicas de Saneamento e de Recursos Hídricos no Brasil. Ambiente \& Sociedade, v. 18, n. 3 p. 193-210, 2015 . https://doi.org/10.1590/1809-4422ASOC1047V1832015.

O'KELLY, B.C. Geotechnics of municipal sludges and residues for landfilling. Geotechnical Research (3), 148-179. 2016. https:// doi.org/10.1680/jgere.16.00013

OLIVEIRA, S. M. A. C.; VON SPERLING, Marcos. Avaliação de 166 ETEs em operação no país, compreendendo diversas tecnologias. Parte 1: análise de desempenho. Engenharia sanitária e ambiental, v. 10, n. 4, p. 347-357, 2005.

REZENDE, S. C.; HELLER, L. O saneamento no Brasil: Políticas e interfaces. Belo Horizonte: Editora UFMG, 2008, 387p.

SMITH, J.; CARLIELL-MARQUET, C. M. A novel laboratory method to determine the biogas potential of iron-dosed activated sludge. 2009. Biores. Tech. (100), 5, 1767 - 1774. https://doi.org/10.1016/j.biortech.2008.10.004

SONG, X.; PAN, Y.; WU, Q. CHENG, Z., MA, W. Phosphate removal from aqueous solutions by adsorption using ferric sludge. Desalination, 280, p. 384 - 390. 2011. https://doi.org/10.1016/j.desal.2011.07.028 